\title{
Monitoring and standards in the NHS: (2) standards
}

\author{
CHARLES D SHAW
}

In my first article last week ( $\mathrm{p} 217$ ) I suggested that planning and evaluation in the National Health Service have, for various political and administrative reasons, become centred on the provision of resources rather than on the way in which these are applied or the results that they obtain. If this emphasis is to change the clinical professions must take part in monitoring the Health Service and be prepared to formulate methods for measuring the quality of clinical organisation as a basis for that monitoring.

Routine use of the word "standard" to refer either to the provision of resources or to the quality of care has blurred the issues. Norms of quantity, efficiency, and resources should be clearly differentiated from standards of quality, effectiveness, and outcomes. Strangely, it is in the middle ground between resource provision and clinical practice that there is the least specific guidance as to what is good or what should be standard. Possibly this is because it includes the no-man's land both among the clinical professions and between them and the administrative services.

Norms of provision have been articulated by individual professional groups, such as for occupational therapy ${ }^{1}$ and for clinical neurophysiology, ${ }^{2}$ and by numerous committees and working parties, particularly for the Cinderella services. Resources are an ingredient in the formula for good services, but so are the attitudes, organisation, and training of staff. ${ }^{3}$ For example, the Hospital Advisory Service-now called the Health Advisory Service-noted wide variations in standards of nursing care even when nurse:patient ratios were the same and reported that, in general, failure of communication was one of the most frequent causes of complaint. ${ }^{4}$ This problem occurs not only up and down the service hierarchy but also between individuals and professional groups. The need to maintain standards in clinical organisation is regularly apparent in reports from the medical defence organisations, the Health Service Commissioner, and committees of inquiry into institutional scandals.

The Royal College of Nursing's working party on standards of nursing care emphasised that in order to be effective and acceptable such standards must be formulated by the professionals themselves and must be explicitly stated. ${ }^{5}$ Since most aspects of health overlap more than one professional group, a third characteristic could be added: that standards should be developed jointly by all disciplines concerned. Again, lack of coordination such as in working policies of professional groups has been amply shown in long-stay hospitals ${ }^{6}$ and could be equally prevalent elsewhere.

\section{Explicit standards of clinical organisation}

During the past few years practical guidelines have been published for various long-stay hospital services. ${ }^{7-12}$ A less generalised but geographically broader approach to promoting good ideas is shown by a project sponsored by the International

Gloucestershire Area Health Authority, Burlington House, Lypiatt Road, Cheltenham GL50 2QN

CHARLES D SHAW, MB, BS, senior registrar in community medicine
Hospital Federation to highlight imaginative mental health schemes throughout the world. ${ }^{13}$

In the acute sector some of the many reports with proposals on obstetric and neonatal care have provided specific practical guidelines ${ }^{14-17}$ but, though they have lately shown more coherence among the medical groups concerned, a single consensus among all disciplines has yet to emerge.

Apart from concerning these patient groups, however, there are few explicit guidelines as to what is a "good" service. An index of practice is planned by the National Association of Health Authorities as a means of exchanging good ideas for solving problems, but so far it is confined primarily to administrative concerns. The requirements of the royal colleges for the accreditation of training posts hint at desirable features such as case records of a "high standard"18 and an "adequate system of medical records" 19 without specifying what is expected. Even the Tunbridge Committee, ${ }^{20}$ which considered the standardisation of hospital medical records and whose membership was predominantly medical, made detailed recommendations on every administrative facet without suggesting what clinical information the records should contain. Similarly, the Guide to Good Practices in Hospital Administration ${ }^{21}$ stops abruptly and dutifully short of suggesting how clinical staff could contribute, for example, to the organisation of the operating theatre.

With the exception of certain areas where standards are inevitably technical, such as in laboratory infection control ${ }^{22}$ and ionising radiation, ${ }^{23}$ it should be possible to formulate general statements of good organisation that are comprehensible, acceptable, and accessible to all staff.

Contrary to assumptions that may seem logical in a nationalised health system, good practices developed in one place have no regular means of "cross-pollination" to another. Without realistic guidelines, which are relevant and accessible to all the personnel concerned, proved ideas either lie fallow or are discovered only by another reinvention of the wheel. Just as norms of provision are not locally sensitive, good practice from one place is not necessarily applicable in another. But it can still offer an objective to be achieved by an alternative route.

Clearly stated practical goals may offer clinicians and administrators an agreed basis for defining priorities (many of which having no revenue consequences, are therefore omitted from fiscal planning). They may also provide an objective yardstick by which one unit may compare itself with another in terms of the organisation of service rather than merely the resources consumed. This is still a step away from measuring clinical outcome but it is considerably closer than norms of provision.

\section{Experience in other health systems}

The concept of developing explicit standards covering large sectors of health services is neither new nor untested. It is the basis of "hospital accreditation," which is common to Australia, Canada, and the United States and which has been commended


can College of Surgeons in 1918 and led to separate programmes for Canada and the United States, directed by representatives of the professional bodies of administrators and clinicians. They are thus independent of the government and, though able to 
exert considerable indirect pressure on individual institutions, cannot force participation or compliance with recommendations.

The development of a similar scheme in Australia is particularly interesting because it is relatively new and its progress reflects many of the problems and misgivings that could also be repeated in Britain. The initial impetus came jointly from the New South Wales branch of the Australian Medical Association (AMA) together with the Hospital Association of the adjacent State of Victoria, both of whom had for some years since the early 1960s been working independently and not very successfully to develop a professional non-governmental organisation to promote standards in hospitals. ${ }^{28}$ In 1973 a federal grant supported the appointment of a full-time executive officer, a commitment that was subsequently assumed by the Kellogg Foundation, thus regaining the programme's independence from the government.

What has now become the Australian Council on Hospital Standards made a slow start. Some critics said that government interest in hospitals already promoted uniform standards, that the public (unlike in North America) had little freedom to choose which hospital they attended, and that the hospitals had very limited resources to upgrade their services anyway. ${ }^{29}$ Furthermore, the State health authorities, which had statutory responsibility for hospitals, viewed with suspicion an organisation that looked as if it intended to tell their hospitals what they should be doing. ${ }^{28}$ Thus, by 1980 the programme which had started in Victoria in 1974 still did not include Tasmania and Western Australia. ${ }^{30}$

Even so, the Medical fournal of Australia was consistent in its support for the project and emphasised its importance from the beginning in 1974 in "asserting the essential role of voluntary agencies .... at a time when some political plans and influences would seem, even though unintentionally, to favour mediocrity." ${ }_{31}$ Four years later it still thought that the medical profession could be justly proud that, through the AMA, it had played a major role as initiator. ${ }^{32}$ Furthermore, an independent evaluation by the University of New South Wales confirmed that the published standards and the survey visits were helpful to hospitals and their staff. ${ }^{30}$

Analysis of 100 visits to public hospitals in three States showed that only half of those with under 350 beds had a medical staff structure adequate to fulfil key responsibilities, and without this numerous other problems were insoluble. Under $60 \%$ of all hospitals had medical records including most basic elements of medical information, and only $25 \%$ used even rudimentary evaluation of clinical performance. Private hospitals fared much worse on these criteria, and patients in private wards of public hospitals were less likely to have adequate records than those in standard wards. These findings, it was suggested, may well be generalised throughout Australia. ${ }^{33}$

However inapplicable the conclusions of such surveys may be to Britain or however different may be the financing of health care in Australia and North America, it is interesting that in each instance the medical professions took the initiative in setting explicit standards for clinical organisation. They co-operated with nursing, administrative, and other professional organisations in doing so, and the programmes have remained independent of the government.

To spell out what we mean by a "good" service in Britain would help to propagate good practices, to describe what we are trying to achieve, and to evaluate what we have achieved. Canada, America, and Australia already have such guidelines. These are mainly hospital orientated, but there is no reason why Britain should not develop the concept into all branches of the Health Service and incorporate them into operational planning at district level.

The most credible source of such guidelines is systematic observation of current practice, but that requires the good will, if not active support, of all clinical professions. If the exercise of collecting, propagating, and sharing ideas in good practices was directed by a council representing the professional organisations it would command far greater support than if, as currently seems to be the assumption, it was under the control, however benign, of the DHSS or health authorities.

There is now a growing demand from politicians and consumers for health services to be accountable and measurable. So now seems an appropriate moment for the royal colleges and professional institutes and associations to consider the value of a joint venture to retain the initiative in setting and evaluating NHS standards.

\section{References}

${ }^{1}$ College of Occupational Therapists. Recommended minimum standards for occupational therapy staff patient ratios. London: COT, 1980.

2 Royal College of Physicians. Recommended minimum standards for departments of clinical neurophysiology in the National Health Service. London: RCP, 1979.

${ }^{3}$ Development Team for the Mentally Handicapped. First report: 1976-77. London: HMSO, 1978.

4 Hospital Advisory Service. Annual report for 1969-70. London: HMSO, 1971

5 Royal College of Nursing. Standards of nursing care. London: RCN, 1980.

${ }^{6}$ Hospital Advisory Service. Annual report for 1972. London: HMSO, 1973.

${ }^{7}$ Royal College of Nursing. Improving geriatric care. $A$ handbook of guidelines. London: RCN, 1975.

${ }^{8}$ National Development Group for the Mentally Handicapped. Mental handicap-planning together. London: HMSO, 1976.

- National Development Group for the Mentally Handicapped. Helping mentally handicapped people in hospital. London: DHSS, 1978.

10 Department of Health and Social Security. Organisation and management problems of mental illness hospitals. London: HMSO, 1980. (Nodder Report.)

${ }^{11}$ Rodgers SJ. Organisation and management problems of mental illness hospitals. London: HMSO, 1980.

12 National Development Group. Improving the quality of services for mentally handicapped people. London: DHSS, 1980.

13 International Hospital Federation. Good practices in mental health. London: IHF, 1980.

14 Royal College of Obstetricians and Gynaecologists. Principles and organisation of general practitioner maternity units and their relation to specialist maternity units. In: A review of the medical services in Great Britain. London: Social Assay, 1962: 243-52.

15 Department of Health and Social Security. Report of the expert group on special care for babies. London: HMSO, 1971. (Sheldon Report.)

16 British Paediatric Association/Royal College of Obstetricians and Gynaecologists Liaison Committees. Recommendations for the improvement of infant care during the perinatal period in the United Kingdom. London: BPA/RCOG, 1978

17 General Medical Services Committee. Maternity Services Subcommittee. General practitioner obstetrics-a policy for the '80s. $\mathrm{Br} M$ Med f 1981; 282:1171-2.

18 Royal College of Surgeons of England. Recognition of posts in hospitals. London: RCS, 1978

19 Joint Committee for Higher Training of Anaesthetists. Higher specialist training. London: RCS, 1979.

20 Central Health Services Council Standing Medical Advisory Committee. The standardisation of hospital medical records. London: HMSO, 1965. (Tunbridge Report.)

21 Department of Health and Social Security. Guide to good practices in hospital administration. London: HMSO, 1970.

22 Department of Health and Social Security. Code of practice for the prevention of infection in clinical laboratories. London: HMSO, 1978. (Howie Report.)

${ }^{23}$ Department of Health and Social Security. Code of practice for the protection of persons against ionizing radiations arising from medical and dental use. London: HMSO, 1972. (Windeyer Report.)

24 Anonymous. Standards of hospital care. British Hospital fournal and Social Services Review 1969;79:478-9.

25 Anonymous. Hospital accreditation. Lancet $1972 ; \mathrm{i}: 1319-20$.

26 Shaw CD. Mark of approval. Health and Social Service fournal 1978;88: 664-6.

27 Anonymous. All change? King's Fund News 1980;3(2):1.

28 Wilson LL. Peer review-an Australian perspective. Med $\mathcal{F}$ Aust 1979; 2:686-9.

29 Steele SK. Accreditation in Australia. National Hospital 1974;18(3):13-7.

30 Duckett SJ, Coombs EM. Hospital attitudes to accreditation. Australian Health Review $1980 ; 3(2): 8-12$.

${ }^{31}$ Anonymous. The Australian hospital standards committee. Med $\mathcal{f}$ Aust $1974 ; 2: 311-2$.

32 Anonymous. Hospital accreditation and Australian hospitals. Med $\mathcal{F}$ Aust $1978 ; 1: 480-1$.

${ }^{33}$ Pickering E. Accreditation survey findings. Australian Health Review $1980 ; 3(2): 13-5$

(Accepted 14 December 1981) 